\title{
Selected poster presentations from the American Association of Applied Linguistics conference, Denver, USA, March 2020
}

\section{Out-of-class peer interactions matter for second language acquisition during short-term overseas sojourns: The contributions of Social Network Analysis*}

\author{
Michał B. Paradowski ${ }^{1 \star}$ (D), Andrzej Jarynowski² (D), Magdalena Jelińska ${ }^{1}$ (D) \\ and Karolina Czopek ${ }^{3}$ (C) \\ ${ }^{1}$ Institute of Applied Linguistics, University of Warsaw, Poland, ${ }^{2}$ Interdisciplinary Research Institute in Wrocław, Poland and \\ ${ }^{3}$ Institute of English Studies, University of Warsaw, Poland \\ ${ }^{\star}$ Corresponding author. Email: m.b.paradowski@uw.edu.pl
}

\section{Motivation}

Second language (L2) or target language (TL) acquisition can take place in different, both educational and leisure settings. One non-negligible context is social interactions in peer learner networks, ${ }^{1}$ particularly in immersion settings (Mitchell, McManus, \& Tracy-Ventura, 2015; Mitchell, Tracy-Ventura, \& McManus, 2017).

A scenario that has been commonly assumed to lead to significant gains in students' language proficiency is residence and study abroad (SA). However, extensive variation has been documented both in the amount of SA students' L2 contact and in their linguistic outcomes (Kinginger, 2009; McManus, 2019). Dewey, Belnap, and Hillstrom (2013) emphasise the need for additional research - a necessity reiterated in a recent synthesis of state-of-the-art papers on language learning in SA contexts (Isabelli-García, Bown, Plews, \& Dewey, 2018).

One of the factors determining L2 success may be the mediating role of communication taking place WITHIN students' social networks. Being involved in social networks, learners share and actively construct knowledge through ongoing social exchanges and collaboration (Coleman, 2015).

\section{Aims}

Skilful development of L2 learners' social networks can accelerate their second language acquisition (SLA), but this possible positive effect may be confounded by other social processes. ${ }^{2}$ The aim of our research is to establish how interactions with peer L2 learners catalyse or inhibit language learning. To this end, we employ computational social network analysis. Unlike some previous notable studies (Dewey, Bown, \& Eggett, 2012, 2013; Zappa-Hollman \& Duff, 2015; Gautier, 2019), we do not limit the scope of enquiry to isolated ego-networks, which only investigate the links between the individual and her/his alters, but we set out to examine the L2 learner network in its entirety, where knowledge of the links between (almost) all network members enables a reconstruction of the connected social graph of the complete learner group.

The overarching research questions posed in this study are:

\footnotetext{
${ }^{*} \mathrm{~A}$ reproduction of the poster discussed is available in the Supplementary Material published alongside this article on Cambridge Core.

(c) The Author(s), 2020. Published by Cambridge University Press. This is an Open Access article, distributed under the terms of the Creative Commons Attribution licence (http://creativecommons.org/licenses/by/4.0/), which permits unrestricted re-use, distribution, and reproduction in any medium, provided the original work is properly cited.
} 
1. What is the impact of the peer interaction network topology on SLA during short-term SA (which kinds of peer interactions favourably impact SLA and which do not)?

2. What are the modifiable factors in TL improvement (can we identify effective strategies for the teacher to moderate learners' peer interactions towards a network structure most beneficial for SLA)?

The findings may deliver practical recommendations for language teachers as to how, by first identifying students' and groups' communication profiles and social interaction patterns, and subsequently seeking ways to reinforce and promote advantageous educational behaviours while discouraging or inhibiting deleterious ones, they could aid learners in their quest to acquire the L2.

\section{Method and population}

The study reported here involved 332 participants in two editions of a 4-week-long intensive summer course of the Polish language and culture in Warsaw (195 students split into 18 groups in the 2017 cohort, 137 in 13 groups in 2019). The social graph data were obtained via questionnaires where the students were asked to declare the direction, intensity and language(s) of out-of-class communication with every other group member, information which was subsequently used to reconstruct the networks established among the students. Additionally, the questionnaires quantified the participants' communication in different contexts and languages, and included items concerning their psychosocial portrait and self-assessed progress. For triangulation purposes, and to obtain a more objective measure, we also acquired their placement and final scores. ${ }^{3}$

In order to investigate learners' peer interactions on the micro- (each individual's ego-network) and meso-levels (complete network of all the students in each group), and subsequently extrapolate the findings to the population, we used Social Network Analysis (SNA), a method commonly applied to interpret the nature of relationships (links) between individuals (nodes) by looking into the interactions that occur between the network members. One's position (importance) in the network can be quantified through a number of network measures ('centralities', see Opsahl, Agneessens, \& Skvoretz, 2010).

The main metric used in this study was weighted degree centrality, i.e. the number of links for each node, considered in two dimensions:

- direction of interaction (incoming, initiated and dominated by peers, or outgoing, initiated by the individual; see arrows in Supplementary Figure 2); and

- language of interaction (proportion of interaction in the TL vs total communication; see the two respective graphs in Supplementary Figure 2).

The dependent variables included subjective improvement in several areas of linguistic competence (overall, in grammar, in vocabulary, in pronunciation, and in pragmatic and cultural knowledge) as well as objective global progress, i.e. standardized difference between placement and final test grades (data completeness: 58\%). Additionally, we included 122 socio-psychological moderating variables. To determine how the variables were associated with performance, we performed single and multiple linear regressions and calculated Pearson correlation coefficients.

\section{Results: influence of network variables (weighted degree centrality) on improvement}

Immersion in the TL culture seems a precondition for L2 peer learning, as interactions with classmates in at-home environments fail to influence TL progress (Paradowski, Jarynowski, Czopek, \& Jelińska, 2020). However, the intensive language course participants do not recognise the communicative dimension of peer learner networks and their influence on their progress; rather, they treat their network as a means of obtaining class notes and collaborative learning (source of cultural capital), but primarily appreciate its social dimension. 


\section{Modifiable factors}

High weighted in-degree in total communication is negatively correlated with various dimensions of subjective improvement (in pronunciation, vocabulary, reading comprehension, cultural knowledge, overall) (see Supplementary Figure 3). A possible explanation may be that the measure reflects network popularity, and search for support and values that are alternative to those conventionally prioritised in educational settings (Coleman, 1961). Participation in social (integrative) activities, however, has a positive influence on L2 progress (Paradowski et al., 2020, under review).

High weighted out-degree in the TL correlates significantly with various dimensions of subjective (grammar, vocabulary, overall, and especially in pronunciation) and objective improvement (Supplementary Figure 3), calling to mind various iterations of Swain's $(1985,1998)$ Output Hypothesis. Conversely, intensity of the teacher's communication with the student in a (non-L1) non-TL reduces L2 improvement (Supplementary Table 1).

High weighted in-degree in the TL has a significant positive impact on objective progress (Supplementary Table 4), proving the importance of the network's information dimension (Merton, 1949/1968). ${ }^{4}$

\section{Results: influence of background variables on social network behaviour}

\section{Non-modifiable variables}

Learners' network profiles are better discernible within homogeneous (e.g. co-nationals') than heterogeneous groups (Paradowski et al., 2020). Participants' patterns of social embeddedness in TL communication are moderated:

- positively by their individual entry TL competence $(p=.07)$ (Supplementary Table 2) and psychosocial portrait (Supplementary Tables 1-3);

- negatively by competence in lingua-franca English (Supplementary Table 1), which provides an easy linguistic 'escape route'.

\section{Modifiable factors}

Weighted out-degree centrality in the TL in interaction with peers is negatively influenced by the frequency of communication with the teacher in a (non-L1) non-target language (Supplementary Table 2). In-degree centrality in turn is positively affected by intensity of talking in the TL to strangers and in service encounters (Supplementary Table 3).

\section{Conclusions and implications}

SNA can meaningfully contribute to practical in- and out-of-class applications. Peer learner networks can have both a positive and a negative impact on L2 acquisition, depending on the context and the network dimension involved, for example:

- a positive predictor of TL improvement is reciprocal out-of-class interactions in the language being acquired;

- outgoing interactions in the TL are a stronger predictor than incoming interactions;

- a clear negative relationship exists between performance and interactions with same-L1 speakers;

- a clear negative relationship exists between L2 performance and weighted in-degree centrality in total communication;

- fluency in lingua-franca English tends to significantly impede progress in the (non-English) TL.

The influence of the social network on L2 improvement in immersion settings is significant in both the communication and the cultural capital dimensions. 
Given the conspicuous relationships, one can recommend that the teacher:

- support multicultural group integration beyond groups of speakers of a shared non-target language (such as co-nationals);

- promote the organisation of and participation in social events;

- avoid using non-L1 non-TL and encourage TL use both in and out of class;

- suppress celebrity tendencies (asymmetric and non-reciprocated incoming interactions reflecting popularity) and support equity in group communication.

Although some of these points may sound straightforward, SNA provides solid evidence for the observed interdependences. The results may assist teachers in choosing the optimal forms of inand out-of-class activities, and raise students' awareness of both more and less trivial relations between their interactions within a group and the effects of learning. While the link between social relations and language acquisition has been universally acknowledged by SLA scholars, SNA offers not only a novel methodology but a whole new insight into the language learning process, demonstrating how network structure and the dynamics of interaction are stronger predictors of TL performance than many individual factors such as attitude or motivation.

Supplementary material. To view supplementary material for this article, please visit https://doi.org/10.1017/ S0261444820000580

Acknowledgements. We thank the Polonicum instructors and students who participated in the study, and Błażej Gałkowski and Alisa Mitchel Masiejczyk for helpful feedback on the poster design. The authors' research is sponsored by SONATA-BIS grant № 2016/22/E/HS2/00034 from the National Science Centre of Poland. Andrzej Jarynowski, Karolina Czopek and Michał B. Paradowski acknowledge support from COST Action 15109, European Cooperation for Statistics of Network Data Science (COSTNET), Andrzej Jarynowski and Michał B. Paradowski from COST Action 15130, Study Abroad Research in European Perspective (SAREP), and Michał B. Paradowski also from COST Action 18232 'Mathematical models for interacting dynamics on networks'.

\section{Notes}

1 For an early recognition of the importance of peer learner networks in the classroom, see Moreno (1934).

2 These include segregation (Schelling, 1971; Spaiser et al., 2018), hierarchy building and power distribution (Merton, 1949/1968), or popularity (Coleman, 1961).

3 The project also has a qualitative component, whose results are reported elsewhere (Paradowski et al., 2020). The data collection protocol has institutional review board clearance.

${ }^{4}$ For instance, fellow students we tend to turn to for information - e.g. to borrow class notes - tend to be the ones who make greater L2 progress (consider the friendship paradox; Feld, 1991).

\section{References}

Coleman, J. A. (2015). Social circles during residence abroad: What students do, and who with. In R. Mitchell, N. Tracy-Ventura, \& K. McManus (Eds.), Social interaction, identity and language learning during residence abroad (pp. 33-54). EUROSLA Monographs Series 4. Amsterdam, Netherlands: European Second Language Association.

Coleman, J. S. (1961). The adolescent society. The social life of the teenager and its impact on education. New York, NY: Free Press.

Dewey, D. P., Belnap, R. K., \& Hillstrom, R. (2013). Social network development, language use, and language acquisition during study abroad: Arabic language learners' perspectives. Frontiers: The Interdisciplinary Journal of Study Abroad, 22(1), 84-110.

Dewey, D. P., Bown, J., \& Eggett, D. (2012). Japanese language proficiency, social networking, and language use during study abroad: Learners' perspectives. Canadian Modern Language Review/La Revue canadienne des langues vivantes, 68(2), $111-137$.

Feld, S. L. (1991). Why your friends have more friends than you do. American Journal of Sociology, 96(6), $1464-1477$.

Gautier, R. (2019). Understanding socialisation and integration through social network analysis: American and Chinese students during a stay abroad. In M. Howard (Ed.), Study abroad, second language acquisition and interculturality (pp. 207-236). Bristol, UK: Multilingual Matters.

Isabelli-García, C., Bown, J., Plews, J. L., \& Dewey, D. P. (2018). Language learning and study abroad. Language Teaching, 51(4), 439-484.

Kinginger, C. (2009). Language learning and study abroad: A critical reading of research. New York, NY: Palgrave Macmillan. McManus, K. (2019). Relationships between social networks and language development during study abroad. Language, Culture and Curriculum, 32(3), 270-284. 
Merton, R. K. (1949/1968). Social theory and social structure. New York, NY: Free Press.

Mitchell, R., McManus, K., \& Tracy-Ventura, N. (2015). Placement type and language learning during residence abroad. In R. Mitchell, N. Tracy-Ventura, \& K. McManus (Eds.), Residence abroad, social networks and second language learning (pp. 115-137). EUROSLA Monographs Series 4. Amsterdam, Netherlands: European Second Language Association.

Mitchell, R., Tracy-Ventura, N., \& McManus, K. (2017). Anglophone students abroad: Identity, social relationships, and language learning. London, UK: Routledge.

Moreno, J. L. (1934). Who shall survive? A new approach to the problem of human interrelations. Washington, DC: Nervous and Mental Disease Publishing.

Opsahl, T., Agneessens, F., \& Skvoretz, J. (2010). Node centrality in weighted networks: Generalizing degree and shortest paths. Social Networks, 32(3), 245-251.

Paradowski, M. B., Jarynowski, A., Czopek, K., \& Jelińska, M. (2020). Peer interactions and second language learning: The contributions of Social Network Analysis in study abroad vs. at-home environments. In R. Mitchell \& H. Tyne (Eds.), Language and mobility: Study abroad in the contemporary European context. Abingdon, UK: Routledge.

Paradowski, M. B., Ochab, J. K., Cierpich, A., \& Chen, C.-C. (under review.). How output outweighs input and interlocutors count in study-abroad SLA: Novel insights from social network analysis of learner interactions.

Schelling, T. C. (1971). Dynamic models of segregation. Journal of Mathematical Sociology, 1(2), 143-186.

Spaiser, V., Hedström, P., Ranganathan, S., Jansson, K., Nordvik, M. K., \& Sumpter, D. J. (2018). Identifying complex dynamics in social systems: A new methodological approach applied to study school segregation. Sociological Methods \& Research, 47(2), 103-135.

Swain, M. (1985). Communicative competence: Some roles of comprehensible input and comprehensible output in its development. In S. Gass \& C. Madden (Eds.), Input in second language acquisition (pp. 235-256). New York, NY: Newbury House.

Swain, M. (1998). The output hypothesis, second language learning and immersion education. In J. Arnau \& J. M. Artigal (Eds.), Els Programes d'immersió: una Perspectiva Europea/Immersion Programs: A European Perspective (pp. 127-140). Barcelona, Spain: Publicacions de la Universitat de Barcelona.

Zappa-Hollman, S., \& Duff, P. A. (2015). Academic English socialization through individual networks of practice. TESOL Quarterly, 49(2), 333-368.

Michał B. Paradowski is an associate professor at the Institute of Applied Linguistics, University of Warsaw, a teacher trainer, and a language teaching consultant for television. His interests include second and third language acquisition research, foreign language teaching, bilingualism and bilingual education, embodied cognition, educational technology, English as a lingua franca, and complexity science. He has given over 170 invited lectures, seminars and workshops in Europe, America, Africa and Asia. Michał's recent edited volumes are Teaching languages off the beaten track (Peter Lang, 2014) and Productive foreign language skills for an intercultural world (Peter Lang, 2015); his latest (2017) monograph appeared under the title M/Other tongues in language acquisition, instruction, and use (Institute of Applied Linguistics, University of Warsaw).

Andrzej Jarynowski is an expert in infectious disease modelling and a specialist in epidemiology from Wrocław. His expertise was solicited by such media outlets as Bloomberg and Reuters, among others. He is interested in the application of social network analysis in various social processes, including that of SLA. Andrzej has also conducted multiple voluntary teaching activities (Polish for foreigners, epidemiological modelling, computational social science, e-health) in Eastern European lowresource settings in Moldova and Ukraine.

Magdalena Jelińska is a psychologist, a translator, and a Ph.D. student at the Institute of Applied Linguistics, University of Warsaw. Her speciality is applied educational psychology. As a practitioner and researcher, she likes to verify theories in practice, currently in the field of foreign language learning. Her interests concern the psychology of SLA, personality and individual differences, developmental and cognitive changes, as well as psychosocial aspects of L2 learning processes. Magda is a member of the Polish Psychological Association, the author of 13 chapters published in refereed monographs, and the co-author of the book Wydłużająca się droga do dorosłości [Extending Path to Adulthood] (Cardinal Wyszyński University Scientific Publishers, 2012).

Karolina Czopek is a Ph.D. student at the Institute of English Studies and a graduate of the Institute of Ethnology and Cultural Anthropology at the University of Warsaw. Her scientific interests revolve around language acquisition by adult learners, with a particular emphasis on old age learners, as well as on implementing ethnography and other qualitative methodologies in language acquisition research. She is currently working on her Ph.D. project on social interactions and English as a foreign language learning in late adulthood.

Cite this article: Paradowski, M. B., Jarynowski, A., Jelińska, M., \& Czopek, K. (2021). Selected poster presentations from the American Association of Applied Linguistics conference, Denver, USA, March 2020. Out-of-class peer interactions matter for second language acquisition during short-term overseas sojourns: The contributions of Social Network Analysis. Language Teaching, 54(1), 139-143. https://doi.org/10.1017/S0261444820000580 